\title{
Antiretroviral treatment adherence and its determinants in Sub-Saharan Africa: a prospective study at Yaounde Central Hospital, Cameroon Mathieu Rougemont*1, Beat E Stoll ${ }^{1}$, Nadia Elia ${ }^{1}$ and Peter Ngang ${ }^{2}$
}

Address: ${ }^{1}$ Institute of Social and Preventive Medicine, CMU, CH-1211 Geneva 4, Switzerland and ${ }^{2}$ Department of Internal Medicine, CNPS Hospital, Yaoundé, Cameroon

Email: Mathieu Rougemont* - redmat22@hotmail.com; Beat E Stoll - beat.stoll@unige.ch; Nadia Elia - nadia.elia@hcuge.ch; Peter Ngang - ngangbmvr@yahoo.co.uk

* Corresponding author

Published: 12 October 2009

AIDS Research and Therapy 2009, 6:21 doi:10.1 186/1742-6405-6-21

This article is available from: http://www.aidsrestherapy.com/content/6/I/2I

(C) 2009 Rougemont et al; licensee BioMed Central Ltd.

This is an Open Access article distributed under the terms of the Creative Commons Attribution License (http://creativecommons.org/licenses/by/2.0), which permits unrestricted use, distribution, and reproduction in any medium, provided the original work is properly cited.
Received: 30 March 2009

Accepted: 12 October 2009

\begin{abstract}
Background: With African health-care systems facing exploding demand for HIV care, reliable methods for assessing adherence and its influencing factors are needed to guide effective public-health measures. This study evaluated individual patient characteristics determining antiretroviral treatment (ART) adherence and the predictive values of different measures of adherence on virological treatment failure in a cohort of patients in a routine-care setting in Cameroon.
\end{abstract}

Methods: Longitudinal study over 6-months following ART introduction, using patients questionnaires and hospital and pharmacy records.

Results: At the end of the 6 months study period, 219 of 312 patients $(70 \%)$ returned to the pharmacy to refill their medication, $17 \%$ (5I) were lost to follow-up, $9 \%$ (28) were dead and $4 \%$ (I4) were transferred to other care centres. Virological treatment failure at 6 months was experienced by 26 patients, representing $13 \%$ of patients with available viral load value. Pharmacy refill irregularity was the most powerful predictor (odds ratio 12.4; $\mathrm{P}<0.00 \mathrm{I}$ ) of virological treatment failure, compared with CD4 cell count increase at 6 months (odds ratio $7.8 ; P=0.002$ ) or self-reported adherence at one month (odds ratio I.I; $P=0.85$ ). Low intensity of $A R T$ side-effects after one month was strongly associated with survival (odds ratio $0.1 \mathrm{I} ; \mathrm{P}=0.00 \mathrm{I}$ ). Patients starting ART with $\mathrm{CD} 4$ cell count $<100$ cells $/ \mathrm{mm}^{3}$ had a greater risk of dying during the follow-up period (odds ratio 2.69; $P=0.02$ ). Compared with asymptomatic $C D C$ stage A patients, $C D C$ stage $B$ (odds ratio 5.72) and CDC stage $C$ patients (odds ratio 16.9) had higher risk of becoming lost to follow-up $(P<0.00 I)$. In the multivariate analyses, pharmacy non-adherence was less frequent in women (adjusted odds ratio $0.56 ; \mathrm{P}=0.05$ ) but more frequent in patients with high monthly income (odds ratio 3.24; $P=0.04$ ).

Conclusion: Pharmacy-refill adherence might be considered as an alternative to CD4 count monitoring for identification of patients at risk of virological failure, especially in resources-scarce countries. The study confirmed the difficulty in demonstrating clear associations of individual patient factors and treatment outcomes. The substantial loss to follow-up and deaths occurring within 6 months after initiating ART emphasise the need to understand the best timing of ART initiation and further elucidate and educate on the underlying reasons for delaying initiation of ART in resource-limited countries 


\section{Background}

During the last decade, access to HIV care in Sub-Saharan Africa has been improved by reduction in the cost of ART and by the implementation of WHO guidelines promoting scaling-up by task shifting for clinical decision-making to less specialised health-care workers [1]. However, the challenge to achieve high adherence to ART is particularly acute in Sub-Saharan Africa as the high rates of HIV/AIDS lead to greater absolute numbers of affected individuals than in other low-income regions. Although long-term good ART adherence has been observed in certain settings of public sectors in Africa (Nachega, data presented at 16th Conference on Retroviruses and Opportunistic Infections 2009), the magnitude of this challenge in Sub-Saharan Africa remains large [2] and there is growing evidence for high rates of patients loss to follow-up [3,4]: a recent review reported that ART programmes in Africa retain only about $60 \%$ of their patients after two years on ART [5].

As in other African countries, the average prevalence of HIV in Cameroon has risen dramatically during the last two decades, from $0.5 \%$ in the early 1990 s to $5.5 \%$ in 2004 [6]. In view of the severe socio-economic and developmental impact of the epidemic, the government of Cameroon has made the fight against HIV/AIDS a priority area in its 2000-2010 strategic plans to combat poverty. Although the cost of drugs has gone through several phases of reduction since a pilot antiretroviral drug delivery programme started in 2000, the implementation of a national decentralisation programme for HIV care in 2006 led to existing health infrastructures being overwhelmed by a huge demand for treatment. The overcrowding of HIV care centres has recently increased, as free treatment began to be available in May 2007.

Adherence to antiretroviral therapy (ART) is crucial to ensure viral suppression, decrease the risk of disease progression and drug resistance. However, it is difficult to measure accurately, which is reflected in the number of conflicting reports available on the response to ART in people living with HIV/AIDS (PLHIV). Optimistic reports [7-11] may have over-emphasised selective publication of positive results [12], or have been biased towards highly motivated patients with early access to limited therapy [13]. Given these methodological difficulties, it is not surprising that a bewildering number of factors have been reported to influence adherence: age; gender; monthly income; level of education; travel time from home to clinic; baseline CD4 cell count; CDC HIV clinical stage before starting ART, type of ART regimen, presence of early ART side-effects and disclosure of HIV status to at least one relative [14-20].
Clearly, there is a need for simple and reliable methods of assessing adherence as well as its influencing factors in order to guide effective public-health measures.

The objective of this study was to compare the diagnostic accuracy of CD4 cell count changes, self-reported adherence and pharmacy refill history to identify patients with virological treatment failure amongst a cohort of PLHIV in a routine care setting in Cameroon during the first 6month follow-up period. We then examined the relationship between patient individual factors and adherence, including in our analysis the substantial number of patients loss to follow-up.

\section{Methods}

\section{Study site, population and design}

The Day Hospital of Yaoundé Central Hospital (YCH) opened in 1998 with a capacity of offering care to 4500 PLHIV. By 2006 this centre had registered more than 10,000 PLHIV, with approximately 2000 patients on ART, resulting in long waiting periods, overburdened staff and a severe shortage of clinic space.

At the time of the study, patients had to pay for care, including drugs (USD 7 to 17 monthly), laboratory tests (USD 50 for pre-treatment check-up) and clinical visits (USD 4 for a ticket valid for one month). Before receiving ART, pre-counselling and post-counselling visits were necessary, followed by three consecutive medical visits and a final socioeconomic inquiry to assess ART readiness. Therapeutic committee determined eligibility for ART based on CDC clinical staging (the classification routinely used in this hospital) and CD4 cell counts.

We recruited all ART-naïve patients at the Day Hospital of YCH between June and September 2006 at their first antiretroviral prescription visit. Exclusion criteria were age under 18 years, imminent transfer to another treatment centre, prior antiretroviral therapy and poor health status, with the patient unable to provide consent and respond to the initial inclusion questionnaire. In most cases the latter patients were hospitalised in a common room that rendered confidentiality difficult.

Routine clinical visits where scheduled on day 15 , at months 1 and 3, and every 3 months thereafter. Antiretroviral therapy was based on triple-drugs regimens consisting of two NRTIs and one non-NRTI and was dispensed only at the central hospital's pharmacy. Patients were provided with more medication than required, i.e. tablets were usually dispensed for 30 days, whereas pharmacy visits were scheduled in multiples of 4 weeks. At each pharmacy visit were registered: date of present prescription refill, prescribed drug regimen and date of the next pharmacy appointment. 
This study was approved by the Cameroon National Ethics Committee and informed written consent was obtained from each participant prior to inclusion into the study.

\section{Data collection}

Biomedical and clinical data were extracted from the clinic file of each enrolled patient and included biochemistry, haematological tests, CD4 cell counts determinations (FacsCount; Becton-Dickinson, San Jose, CA, USA), date of death or transfer to another health centre. Determination of CD4 cell levels were performed at the pretreatment examination and routinely requested every 6 months thereafter. Plasma viral load assays (Abbott Real Time HIV-1 assay) were offered to all study participants after $\geq 5$ months of ART.

At the day of introducing ART, three trained study interviewers administered an initial questionnaire exploring socioeconomic status, knowledge and beliefs toward HIV and ART, social support and disclosure of HIV status $[21,22]$.

A second culturally adapted questionnaire gathered information on self-reported ART adherence and early ART side-effects [23]. It was administered after one month of therapy by a PLHIV external to the health care team. We asked whether or not any ART had been missed, using global one-month recall. All interviews were conducted in either French or English, the two national languages in Cameroon.

Pharmacy records were reviewed 6 months after ART initiation to define pharmacy-refill adherence. In order to further ascertain true adherence status, patients without renewed prescriptions in the last two months were actively traced by two phone calls and if still alive, encouraged to come back to the clinic to restart therapy.

\section{Outcome definitions}

Virological treatment failure was defined as a viral load $>400$ copies/ml (lower detection limit of 40 copies $/ \mathrm{ml}$ ), and was used as the gold standard to compare different methods of adherence measurements: CD4 count change, self reported adherence and pharmacy-refill history. Immunological treatment failure was defined as a reduction in CD4 count after 6-months of treatment to, or below, pre-therapy baseline, or persistent levels below 100 cells $/ \mathrm{mm}^{3}[1]$.

Self-reported adherence was classified as "adherent" when not a single dose was missed or non-adherent if the patient admitted having missed at least one dose during the last month.
Pharmacy non-adherence was defined as renewal of prescriptions of later than 2 weeks after the scheduled pharmacy appointment, or patients confirming abandoned ART on phone call tracing. Patients not traced by phone calls were considered to be lost to follow-up. The followup time was censored at the last scheduled pharmacy visit.

\section{Statistical Analysis}

Statistical analyses were conducted using STATA version 9 (Texas, USA).

The three different methods to measure adherence were compared in their ability to predict virological failure by computing their sensitivity and specificity, positive and negative predictive values and positive and negative likelihood ratios. Finally, the association between each method and virological failure was also reported as OR and 95\% confident interval. We then used the method of adherence assessment showing the strongest association with virological failure as a surrogate of true treatment adherence. Chi-square tests were used to determine the associations between each individual patient baseline characteristic and adherence, at a $\mathrm{P}<0.2$ level of significance. Logistic regression models were fitted including characteristics shown to be associated with adherence in univariate analysis $(\mathrm{P}<0.2)$. Variables measured at one month were excluded from this analysis as the substantial number of patients with early loss to follow-up reduced the number of available data and thus statistical power.

As the substantial rate of patients loss to follow-up may introduce bias into estimates of risk factors for treatment non-adherence, we conducted a sensitivity analysis where associations were tested in two scenarios: a best-case scenario, where all patients lost to follow-up and not successfully traced by phone call were considered as adherent, and a worst-case scenario where all such patients were defined as non-adherent [Fig. 1].

\section{Results}

\section{Baseline characteristics}

Patient's disposition is shown in [Fig 1]. Of the 434 patients selected to receive ART between June and September 2006, 405 (93\%) attended the baseline visit and 312 $(72 \%)$ were included in the study. Reasons for non participation of eligible patients were imminent transfer to another treatment centre $(n=20)$, first antiretroviral prescription by a physician not participating in the study ( $\mathrm{n}$ $=15$ ), a physical health status rendering long interviews difficult for the patient $(n=11)$, refusal to take part $(n=$ $8)$ and other reasons $(n=39)$.

Among the 312 enrolled patients at the start of ART, the mean age $( \pm S D)$ was $37 \pm 9$ years, with a majority of 


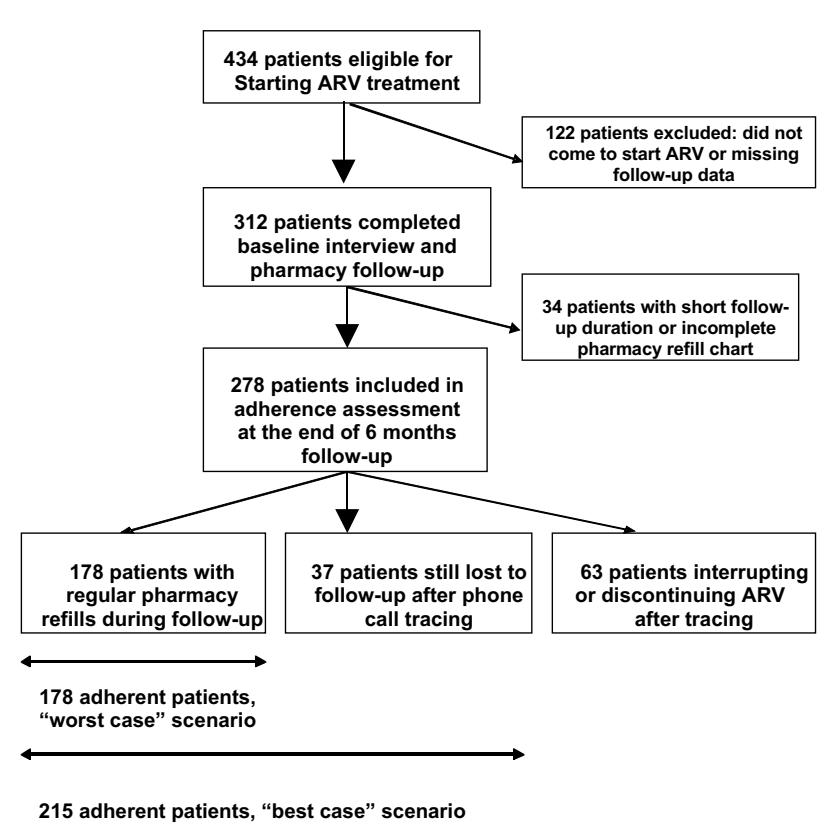

Figure I

Flow chart for adherence analysis.

women (63\%) [Table 1]. Although 97 participants (31\%) reported no income-generating occupation, $76(78 \%)$ of these received occasional or regular financial help from relatives. Thirty-two patients $(10 \%)$ benefited from treatment support from the Global Fund, which was associated with neither socio-economic status nor with income levels (data not shown). Forty-six per cent of the cohort had the lowest financial income (monthly income of less than USD50). About two-thirds of the patients (70\%) lived close to the clinic, with only 15 (5\%) living more than 4 hours from the Day Hospital by public transport.

Most patients ( $\mathrm{n}=195$ or $63 \%$ ) had been followed at the clinic for less than one month before initiating ART. However, only 36 patients (12\%) reported the use of alternative therapies for HIV in the past. At the time of starting ART the majority of the cohort were classified as symptomatic (64\% at CDC stage B and $14 \%$ at stage C), the median baseline CD4 count was 104 cells $/ \mathrm{mm}^{3}$ (interquartile range $50-177$ cells $/ \mathrm{mm}^{3}$ ). All patients received two nucleoside reverse transcriptase inhibitors (NRTIs) and one non-nucleoside reverse transcriptase inhibitor (NNRTI) with the exception of one patient who received two NRTIs and one protease inhibitor.

When asked about social support and stigmatisation, 275 participants (88\%) reported having disclosed their HIV status to at least one person and $260(83 \%)$ declared satisfied by family or friends support. Most patients $(n=258$ or $80 \%$ ) had optimistic expectations of the effects of ART on their health status, a sizable minority believed that
Table I: Socio-demographic and clinical data at start of ART of the 312 patients studied

\begin{tabular}{|c|c|c|}
\hline Characteristics & $\mathbf{n}$ & $\%$ \\
\hline \multicolumn{3}{|l|}{ Age groups (year) } \\
\hline$<30$ & 65 & 21 \\
\hline $30-49$ & 199 & 64 \\
\hline$\geq 50$ & 32 & 10 \\
\hline Missing data & 16 & 5 \\
\hline \multicolumn{3}{|l|}{ Gender } \\
\hline Male & 106 & 34 \\
\hline Female & 198 & 63 \\
\hline Missing data & 8 & 3 \\
\hline \multicolumn{3}{|l|}{ Marital status } \\
\hline Single, Divorced, Separated & 182 & 58 \\
\hline Married, Cohabiting & 114 & 37 \\
\hline Missing data & 16 & 5 \\
\hline \multicolumn{3}{|l|}{ Level of education } \\
\hline Primary & 91 & 29 \\
\hline Secondary without Bachelor & 156 & 50 \\
\hline Secondary with Bachelor or University & 45 & 15 \\
\hline Missing data & 20 & 6 \\
\hline \multicolumn{3}{|l|}{ Monthly income } \\
\hline$<$ USD 50 & 145 & 46 \\
\hline USD50 - USD I25 & 73 & 23 \\
\hline > USD I 25 & 77 & 25 \\
\hline Missing data & 17 & 6 \\
\hline \multicolumn{3}{|l|}{ Travel time (home to clinic) (h) } \\
\hline$<1$ & 217 & 70 \\
\hline I-4 & 68 & 21 \\
\hline$>4$ & 15 & 5 \\
\hline Missing data & 12 & 4 \\
\hline \multicolumn{3}{|l|}{ Time of follow-up before ART } \\
\hline$<$ I month & 195 & 63 \\
\hline I-6 months & 86 & 27 \\
\hline$>6$ months & 20 & 6 \\
\hline Missing data & 11 & 4 \\
\hline \multicolumn{3}{|l|}{ CDC Stage } \\
\hline A & 57 & 18 \\
\hline B & 201 & 64 \\
\hline C & 44 & 14 \\
\hline Missing data & 10 & 4 \\
\hline \multicolumn{3}{|l|}{ CD4 baseline Strata (cells/mm³) } \\
\hline$<100$ & 143 & 46 \\
\hline $100-200$ & 109 & 35 \\
\hline$>200$ & 47 & 15 \\
\hline Missing data & 13 & 4 \\
\hline
\end{tabular}

treatment could cure HIV (44\%) and 118 patients (38\%) were unaware of possible ART side effects.

\section{Treatment outcomes and adherence measures}

Of 312 patients in the initial cohort, 219 (70\%) were still coming to the pharmacy to refill their medication after 6 months of follow-up, while 51 (17\%) were lost, 28 (9\%) 
had died and 14 (4\%) were had been transferred to other care centres. The incidence rate of loss to follow-up was 40.1 per 100 persons years (95\% CI: 30.5 - 52.8) and mortality rate was 21.2 per 100 persons years $(95 \%$ CI: 15 31 ). Drop-out occurred at a median of 44 days (IQR: 28 80 days) and death occurred at a median of 55 days (IQR: 28 - 81 days) after treatment initiation.

The first routinely scheduled follow-up CD4 cell count was performed by only 71 patients $(23 \%$ of patients still followed-up). The median rise in CD4 cell count from baseline to this point was 117 cells $/ \mathrm{mm}^{3}$ and 16 patients (22\%) with available follow-up CD4 cell count met criteria for immunological treatment failure. Using phone call tracing alongside tracking of patients during regular follow-up visits, we obtained viral load values for 206 patients. Virological treatment failure (viral load value of $>400$ copies $/ \mathrm{ml}$ ) at 6 months was experienced by 26 patients, representing $13 \%$ of patients with available viral load value and $8 \%$ of the entire cohort.

Self-reported adherence data after one month of therapy were obtained for 238 patients $(76 \%)$. The majority of respondents $(78 \%)$ claimed not to have missed a single dose during this period. The proportion of participants that reported full adherence to treatment during the past month decreased from $83 \%$ at one month to $57 \%$ at 6 months.

Adherence based on pharmacy refill charts after 6 months of follow-up could be analysed for 278 participants. Twenty-eight subjects were excluded because of their short follow-up duration ( $<2$ months) and 6 patients had incomplete data on the refill chart [Fig 1]. Two-thirds $(64 \%)$ of patients assessed came regularly every month within two weeks of the pharmacy-appointed dates and qualified as adherent in the analysis. Non-adherence (interruptions or discontinuations) was defined for $23 \%$ of the participants with available data: 49 subjects interrupted their treatment for at least 3 weeks during the follow-up period; 14 patients lost to follow-up could be traced by phone calls and confirmed they had discontinued ART. Thirty-seven patients (14\%) could not be traced by phone call after loss from pharmacy follow-up.

Adherence measurements and virological treatment failure There were significant differences between the ability of different measures of adherence to predict virological treatment failure after 6 months of therapy [Table 2]. Pharmacy-refill irregularity was the most powerful predictor (OR, 12.40; 95\% CI, 4.75-32.40; $\mathrm{P}<0.001)$. In the sub-sample of 194 patients whose 6-month viral load and

Table 2: Potential predictors associated with virological treatment failure ( $>400$ HIV RNA cop/ml) after 6 months of initiating ART

\begin{tabular}{|c|c|c|c|c|c|c|}
\hline & \multicolumn{2}{|c|}{ Self reported adherence } & \multicolumn{2}{|c|}{ CD4 count change } & \multicolumn{2}{|c|}{ Pharmacy refill history } \\
\hline & $100 \%$ & $<100 \%$ & $\begin{array}{l}\text { Immunological } \\
\text { success }\end{array}$ & $\begin{array}{c}\text { Immunological } \\
\text { failure }\end{array}$ & $\begin{array}{c}\text { Regular, } \\
\text { continuous }\end{array}$ & $\begin{array}{l}\text { Irregular or } \\
\text { interrupted }\end{array}$ \\
\hline Total (Nb) & 140 & 25 & 51 & 14 & 147 & 47 \\
\hline $\begin{array}{l}\text { Virological success } \\
\text { (Nb) }\end{array}$ & 125 & 22 & 44 & 6 & 140 & 29 \\
\hline $\begin{array}{l}\text { Virological failure } \\
(\mathrm{Nb})\end{array}$ & 15 & 3 & 7 & 8 & 7 & 18 \\
\hline OR (95\%CI) & \multicolumn{2}{|c|}{$1.13(0.30-4.25)$} & \multicolumn{2}{|c|}{$7.78(1.68-36.0)$} & \multicolumn{2}{|c|}{$12.4(4.75-32.4)$} \\
\hline Sensitivity & \multicolumn{2}{|c|}{0.17} & \multicolumn{2}{|c|}{0.53} & \multicolumn{2}{|c|}{0.72} \\
\hline Specificity & \multicolumn{2}{|c|}{0.85} & \multicolumn{2}{|c|}{0.88} & \multicolumn{2}{|c|}{0.83} \\
\hline $\begin{array}{l}\text { Positive predictive } \\
\text { value }\end{array}$ & \multicolumn{2}{|c|}{0.12} & \multicolumn{2}{|c|}{0.57} & \multicolumn{2}{|c|}{0.38} \\
\hline $\begin{array}{l}\text { Negative } \\
\text { predictive value }\end{array}$ & \multicolumn{2}{|c|}{0.83} & \multicolumn{2}{|c|}{0.86} & \multicolumn{2}{|c|}{0.95} \\
\hline $\begin{array}{l}\text { Positive likelihood } \\
\text { ratio }\end{array}$ & \multicolumn{2}{|c|}{1.13} & \multicolumn{2}{|c|}{1.23} & \multicolumn{2}{|c|}{4.23} \\
\hline $\begin{array}{l}\text { Negative likelihood } \\
\text { ratio }\end{array}$ & \multicolumn{2}{|c|}{0.97} & \multicolumn{2}{|c|}{0.53} & \multicolumn{2}{|c|}{0.34} \\
\hline
\end{tabular}

Viral load measurement was available for 206 patients. Immunological success means a rise above 100 cells/ $\mu$; immunological failure means a drop to pre-treatment levels or $<100$ cells/ $\mu \mathrm{l}$,) 
pharmacy refill charts were available, $38 \%$ of the pharmacy non-adherent patients demonstrated virological treatment failure while 95\% of pharmacy adherent patients presented with virological suppression. Immunological treatment failure was also significantly associated with virological treatment failure (OR, 7.78; 95\% CI,
1.68-36.0; $\mathrm{P}=0.002$ ). However, pharmacy adherence estimated by pharmacy refill charts had greater accuracy for detecting virological treatment failure than CD4 count changes at 6 -months: the sensitivity was higher $(72 \%$ versus $53 \%$ ) with approximately the same specificity ( $82 \%$ versus $88 \%$ ).

Table 3: Logistic regression of patient characteristics associated with treatment outcomes in the first 6 months after initiating ART

\begin{tabular}{|c|c|c|c|c|}
\hline \multirow[t]{2}{*}{ Characteristics } & \multicolumn{2}{|c|}{ Disappeared $(n=51)$} & \multicolumn{2}{|c|}{ Died $(n=28)$} \\
\hline & $\begin{array}{l}\text { Odds ratio } \\
(95 \% \mathrm{Cl})\end{array}$ & P-value & $\begin{array}{l}\text { Odds ratio } \\
(95 \% \mathrm{Cl})\end{array}$ & P-value \\
\hline Age (years) & & 0.65 & & 0.23 \\
\hline$<30$ & $0.98(0.45-2.15)$ & & $0.39(0.11-1.35)$ & \\
\hline $30-49$ & 1 & & 1 & \\
\hline$\geq 50$ & $1.55(0.61-3.96)$ & & $0.58(0.13-2.65)$ & \\
\hline Sex & & 0.09 & & 0.37 \\
\hline Male & I & & I & \\
\hline Female & $0.58(0.31-1.08)$ & & $0.68(0.30-1.55)$ & \\
\hline Monthly income (USD) & & 0.9 & & 0.43 \\
\hline$<$ USD50 & $1.19(0.55-2.59)$ & & $0.92(0.32-2.63)$ & \\
\hline USD50 - USDI 25 & 1 & & 1 & \\
\hline$>$ USDI 25 & $1.09(0.44-2.68)$ & & $1.67(0.57-4.90)$ & \\
\hline Education & & 0.44 & & 0.51 \\
\hline Primary & 1 & & 1 & \\
\hline Secondary without bachelor & $1.38(0.67-2.84)$ & & I.7I (0.64-4.58) & \\
\hline Secondary with bachelor or university & $0.79(0.26-2.39)$ & & $1.77(0.49-6.01)$ & \\
\hline Travel time to clinic (hour) & & 0.47 & & 0.97 \\
\hline$<1$ & I & & I & \\
\hline $\mathrm{I}-4$ & $1.30(0.62-2.72)$ & & $\mathrm{I} .02(0.39-2.7 \mathrm{I})$ & \\
\hline$>4$ & $1.93(0.65-5.75)$ & & $1.22(0.26-5.77)$ & \\
\hline Baseline CD4-cell count (cells $/ \mu \mathrm{I})$ & & 0.86 & & 0.02 \\
\hline$<100$ & $1.06(0.57-1.97)$ & & $2.69(1.12-6.44)$ & \\
\hline$\geq 100$ & 1 & & 1 & \\
\hline Clinical stage & & $<0.001$ & & 0.11 \\
\hline CDC stage $A$ & I & & I & \\
\hline$C D C$ stage $B$ & $5.72(1.33-24.70)$ & & $2.08(0.59-7.35)$ & \\
\hline CDC stage $C$ & $16.9(3.58-80.30)$ & & $4.52(1.04-19.70)$ & \\
\hline ART side-effects at I month & & 0.71 & & 0.638 \\
\hline No side-effects & I & & I & \\
\hline One or more side-effects & $1.24(0.40-3.85)$ & & $1.43(0.30-6.73)$ & \\
\hline ART side-effects at I month & & 0.14 & & 0.001 \\
\hline Improving & $0.49(0.19-1.26)$ & & $0.11(0.02-0.52)$ & \\
\hline Not improving & $\mathrm{I}$ & & 1 & \\
\hline Disclosure of HIV status & & 0.22 & & 0.93 \\
\hline Yes & 1 & & 1 & \\
\hline No & $1.10(0.95-1.27)$ & & I.0I (0.79-1.29) & \\
\hline
\end{tabular}

Patients who disappeared $(n=5 I)$ or died $(n=28)$ are compared with patients with complete follow-up or transferred $(n=233)$. OR were calculated using logistic regression, $\mathrm{p}$-values from the likelihood ratio test. 
Notably, self-reported adherence at 1 month was not significantly associated with virological treatment outcomes.

\section{Associations between patient characteristics, retention and mortality}

Univariate analysis of individual patient factors [Table 3] showed that the most significant factor associated with survival was the improvement of early ART side-effects, (OR: 0.11 ; 95\% CI: 0.02-0.52). Patients starting treatment with CD4 cell count below 100 cells $/ \mathrm{mm}^{3}$ were at significantly greater risk of death during the follow-up period (OR: 2.69; 95\% CI: 1.12-6.44). We found only a trend for association of HIV CDC stage with mortality. However, HIV CDC clinical stage at the beginning of treatment significantly predicted $(\mathrm{P}<0.001)$ loss to follow-up: compared with asymptomatic patients CDC stage A, CDC stage B patients (OR: 5.72; 95\% CI: 1.33-24.70) and specially CDC stage C patients (OR: 16.90 ; $95 \%$ CI: 3.5880.30) had greater rates of loss to follow-up.

There was a non-significant trend to lower rates of interruption of follow-up for women (OR: 0.58; 95\% CI: 0.311.08 ) and for those reporting improving ART side-effects after one month of treatment (OR: 0.49; 95\% CI: 0.191.26). None of the socio-economic determinants studied appeared to influence patient retention and mortality: neither age, nor level of education, nor economic situation and social support were significantly associated with loss to follow-up or with death.

\section{Associations between patient characteristics and pharmacy adherence}

As patients lost to follow-up may have introduced bias into the analysis, we analysed the association of individual patient characteristics with pharmacy adherence in a sensitivity analysis, using two scenarios, a best-case and a worst-case scenario [Table 4]. In the best-case scenario, where all participants lost to follow-up were analysed as adherent, greater age (OR: 0.38; 95\% CI: 0.11-1.33), female sex (OR: 0.66; 95\% CI: 0.37-1.18) and patients reporting improvement of early ART side-effects (OR: 0.51; 95\% CI: 0.23-1.10) tended keep pharmacy appointments less irregularly $(\mathrm{P}<0.2)$. In this scenario, a monthly middle income was significantly associated $(\mathrm{P}=0.01)$ with greater pharmacy adherence. Low (OR: 2.49; 95\% CI: 1.03-6.01) or high (OR: 3.76; 95\% CI: 9.58) incomes groups showed a higher risk for pharmacy non-adherence. In the worst-case scenario, female sex (OR: 0.60; 95\% CI: 0.35-1.01) and improving early ART side-effects (OR: 0.47; 95\% CI: 0.24-0.95) were characteristics associated $(\mathrm{P}<0.05)$ with lower pharmacy non-adherence. CDC stage B patients (OR: 2.68; 95\% CI: 1.26-5.68) and specially CDC stage C patients (OR: 5.13; 95\% CI: 2.0213.00) had higher risk of pharmacy non-adherence than asymptomatic patients.
In the multivariate analysis [Table 5], women presented lower risk for non-adherence both in the best case (adjusted OR: 0.56; 95\% CI: 0.29-1.07; P = 0.08) and in the worst case scenarios (adjusted OR: 0.56; 95\% CI: 0.311.02; $\mathrm{P}=0.05)$. Economic status, in particular patients with the highest monthly income when compared with monthly middle income (OR: 3.24; 95\% CI: 1.24-8.46; P $=0.04$ ), was retained as a predictor of poor adherence only in the best case scenario. When compared with asymptomatic patients, the multivariate analysis confirmed a marked risk of non-adherence for CDC stage B patients (OR: 2.75 ; 95\% CI: 1.23-6.18) and CDC stage C patients (OR: 5.07 ; 95\% CI: 1.87-13.80) in the worst-case scenario $(P=0.003)$.

\section{Discussion}

Despite substantial improvements in the affordability and availability of ART in recent years, African health-care systems face enormous challenges in the context of exploding demand for HIV care [24]. The main objective of this study was to identify factors influencing ART adherence and evaluate related outcome of therapy 6 months after ART initiation in a routine setting.

\section{Treatment outcomes and adherence measurements}

Our cohort showed a relative low patient retention rate: $70 \%$ of the patients who started ART still came to the pharmacy to take their prescription after six months of follow-up, 17\% disappeared, 9\% died and 4\% were referred to other care centres. These results confirm that most losses to follow-up and deaths occur during the initial period after ART initiation.

A recent systematic review [5] of 33 earlier cohorts in developing countries reported a mean retention rate of $79 \%$ at six months. Our slightly lower retention rates may be due to the increasing challenge of managing growing numbers of patients treated.

Pharmacy-refill history gives no description of daily adherence to treatment, because patients may not take all prescribed medications. It could also be considered as a time-consuming monitoring tool for the pharmacy staff, owing to the rapidly growing number of patients in public ART programs. However, this is a simple, inexpensive approach and it was previously reported to be as accurate as $\mathrm{CD} 4$ counts for predicting virological response [25]. We found the same correlation between pharmacy-refill adherence and virological outcome at 6 months. In our settings, pharmacy-refill adherence had even greater accuracy, with higher sensitivity and similar specificity to CD4 count changes at 6 months for predicting virological treatment failure. Moreover, data from refill charts in routinecare conditions were available for $95 \%$ of the participants, whereas only $23 \%$ of the cohort performed their first CD 4 cell count follow-up, an analysis that patients had to cover 
Table 4: Patient characteristics associated with pharmacy non-adherence during the first 6 months after initiating ART

\begin{tabular}{|c|c|c|c|c|}
\hline \multirow[t]{2}{*}{ Characteristics } & \multicolumn{2}{|c|}{ Best-case scenario } & \multicolumn{2}{|c|}{ Worst-case scenario } \\
\hline & OR (95\%Cl) & P-value & OR $(95 \% \mathrm{Cl})$ & P-value \\
\hline Age (years) & & 0.09 & & 0.95 \\
\hline$<30$ & $1.45(0.74-2.83)$ & & $1.05(0.57-1.95)$ & \\
\hline $30-49$ & 1 & & 1 & \\
\hline$\geq 50$ & $0.38(0.11-1.33)$ & & $0.90(0.40-2.04)$ & \\
\hline Sex & & 0.17 & & 0.05 \\
\hline Male & I & & I & \\
\hline Female & $0.66(0.37-1.18)$ & & $0.60(0.35-1.01)$ & \\
\hline Monthly income (US\$) & & 0.01 & & 0.08 \\
\hline < USD 50 (20'000 FCFA) & $2.49(1.03-6.01)$ & & $1.73(0.89-3.38)$ & \\
\hline USD 50 - USDI25 (20'000-50'000) & 1 & & I & \\
\hline$>$ USD I $25\left(>50^{\prime} 000\right)$ & $3.76(1.47-9.58)$ & & $2.27(1.08-4.77)$ & \\
\hline Education & & 0.82 & & 0.16 \\
\hline Primary & 1 & & 1 & \\
\hline Secondary without Bachelor & $0.96(0.51-1.83)$ & & $1.35(0.76-2.37)$ & \\
\hline Secondary with Bachelor or University & $0.74(0.28-1.95)$ & & $0.64(0.27-1.54)$ & \\
\hline Travel time to clinic (hour) & & 0.21 & & 0.73 \\
\hline$<1$ & I & & I & \\
\hline $1-4$ & $0.88(0.44-1.78)$ & & $1.24(0.68-2.61)$ & \\
\hline$>4$ & $0.22(0.03-1.74)$ & & $1.29(0.44-3.79)$ & \\
\hline Baseline CD4-cell count (cells/ $\mu \mathrm{l})$ & & 0.75 & & 0.85 \\
\hline$<100$ & $1.09(0.62-1.93)$ & & $1.05(0.64-1.73)$ & \\
\hline$\geq 100$ & 1 & & I & \\
\hline Clinical stage & & 0.44 & & 0.001 \\
\hline CDC stage $A$ & 1 & & I & \\
\hline CDC stage $B$ & $1.60(0.72-3.55)$ & & $2.68(1.26-5.68)$ & \\
\hline CDC stage $C$ & $1.72(0.62-4.75)$ & & $5.13(2.02-13.0)$ & \\
\hline \multicolumn{5}{|l|}{ Initial ART regimen } \\
\hline Twice daily & 1 & 0.81 & 1 & 0.79 \\
\hline Three times daily & $0.93(0.53-1.64)$ & & $1.07(0.65-1.75)$ & \\
\hline Occurrence of ART side-effects at I month & & 0.46 & & 0.64 \\
\hline No side-effects & I & & I & \\
\hline One or more side-effects & $0.74(0.34-1.62)$ & & $0.84(0.4 I-1.73)$ & \\
\hline Course of ART side-effects at I month & & 0.09 & & 0.04 \\
\hline Improving & $0.5 I(0.23-1.10)$ & & $0.47(0.24-0.95)$ & \\
\hline Not improving & I & & I & \\
\hline \multicolumn{5}{|l|}{ Reported ART adherence at I month } \\
\hline $100 \%$ & I & 0.55 & I & 0.19 \\
\hline$<100 \%$ & $1.30(0.56-3.01)$ & & $1.66(0.78-3.52)$ & \\
\hline Disclosure of HIV status & & 0.82 & & 0.38 \\
\hline Yes & 1 & & I & \\
\hline No & $0.98(0.81-1.18)$ & & $1.07(0.92-1.24)$ & \\
\hline
\end{tabular}

Non-adherent patients are compared with adherent patients in a best and a worst case scenario (best-case scenario: patients lost to follow-up were considered adherent; worst-case scenario: patients lost to follow-up were considered non-adherent). The associations of each characteristic with time stayed adherent were examined using logistic regression models. 
Table 5: Multivariate logistic regression of baseline characteristics associated $(P<0.2)$ with pharmacy non-adherence in the univariate analysis

\begin{tabular}{|c|c|c|c|c|}
\hline \multirow[t]{2}{*}{ Characteristics } & \multicolumn{2}{|c|}{ Best-case scenario } & \multicolumn{2}{|c|}{ Worst-case scenario } \\
\hline & $\begin{array}{c}\text { Adjusted OR } \\
(95 \% \mathrm{Cl})\end{array}$ & P-value & $\begin{array}{c}\text { Adjusted OR } \\
(95 \% \mathrm{Cl})\end{array}$ & P-value \\
\hline Sex & & 0.08 & & 0.05 \\
\hline Male & 1 & & 1 & \\
\hline Female & $0.56(0.29-1.07)$ & & $0.56(0.31-1.02)$ & \\
\hline Monthly income (USD) & & 0.04 & & 0.28 \\
\hline$<$ USD50 & $2.04(0.82-5.06)$ & & $1.66(0.80-3.44)$ & \\
\hline USD50 - USDI 25 & 1 & & 1 & \\
\hline > USDI 25 & $3.24(1.24-8.46)$ & & $1.86(0.82-4.22)$ & \\
\hline Clinical stage & & & & 0.003 \\
\hline CDC stage $A$ & & & 1 & \\
\hline CDC stage $B$ & & & $2.75(1.23-6.18)$ & \\
\hline CDC stage $C$ & & & $5.07(1.86-13.8)$ & \\
\hline
\end{tabular}

at their own expense. The ability of adherence monitoring from the pharmacy to identify patients at risk of treatment failure may help health-care providers for early adherence counselling interventions. At the time of the study, data from refill charts were kept at the Central Pharmacy and were not communicated to clinicians. A practical implication of our findings is that systematic monitoring of pharmacy-refill adherence should be integrated into therapeutic score cards carried by every patient.

Self-reported adherence has been described in several studies as a rapid and inexpensive method, albeit subject to social-desirability and recall biases [26,27]. In our cohort, self-reported adherence was not predictive of virological treatment failure. One earlier study in a South African cohort [28], found only a modest increase in risk (unadjusted OR: 2.35, 95\% CI: 1.52-2.53) for patients reporting $<100 \%$ at 6 weeks for virological failure at 12 months, which might not have been detectable in our smaller population. In addition, the proportion of our participants that reported $100 \%$ adherence to treatment during the past month decreased from $83 \%$ at one month to $57 \%$ at 6 months. Mannheimer [27] described a similar decline in self-reported adherence with time. It is likely that these decreases reflect decreases in true daily adherence with time. However, there may also have been an overestimation of self-reported medication in early stages due to desire to please when patients do not feel confident in a new environment. Further studies in lower-income settings are needed to verify the accuracy of self-reported medication adherence as a predictor of virological outcome.

\section{Determinants of ART adherence}

We examined determinants of adherence in two scenarios to reduce bias due to loss to follow-up. We identified female sex, middle monthly income and less ART related side-effects at one month as predictors of higher pharmacy adherence under both scenarios. Age and HIV clinical CDC stage correlated with pharmacy adherence only under best and worst-case scenarios, respectively. Gender remained of borderline significance after adjusting for potential confounders in the multivariate model.

To the best of our knowledge, the current study is the first to demonstrate that income may not be linearly associated with adherence: patients with monthly middle income had greater pharmacy adherence rates than both the poorest and the richest participants. A recently published meta-analysis [17] examined the association between socio-economic status and adherence to antiretroviral therapy: out of 8 studies, only 2 prospective studies identified low income as a predictor of non-adherence. All, except one [29], analysed income as a binary variable which could explain why none of them described our Ushaped association. Selection bias through restricted financial access to health care seems unlikely in our settings: two-thirds $(67 \%)$ of patients reported no or occasional income, whereas only $25 \%$ of our population reported earning more than USD125 per month.

With the exception of a trend towards greater loss rates among men, we failed to demonstrate any other social or demographic association with loss to follow-up. The same gender association with both death and loss to follow-up was recently reported from a study in Malawi [30].

\section{Limitations of the study areas of uncertainty}

It is unclear how far our results can be generalised to other countries and healthcare systems. Compared with reports from patients starting ART in other treatment programmes in lower-income countries [2], our cohort had a lower 
proportion of men, fewer patients at clinical advanced disease stages and higher baseline CD4 cell counts.

The percentage of male patients in our cohort reflects the gender distribution of HIV prevalence in Cameroon, which indicates that women's access to health care for HIV is improving. We also observed discrepancies between biological (CD4 counts) and clinical (CDC stages) levels of disease in our participants: Only 14\% of our patients started therapy at CDC clinical stage C, despite a median CD 4 cell count of 107 cells/ $\mu$ l. The simplest explanation for this is an underestimation of CD4 cell count at the Day Hospital Laboratory. This conclusion is supported by our observation of a large variability of baseline CD4 cell counts for patients who were analysed at close intervals at different laboratories (data not shown). A lack of association between immunological and virological outcomes have been found in similar settings [3] suggesting that CD4 cell count follow-up should be interpreted with caution, particularly if performed in different laboratories. An alternative explanation would be a systematic clinical misclassification of patients. This is supported by the observation that 75 of 169 patients (44\%) enrolled at the YCH Day hospital between 2001 and 2003 were classified as CDC clinical stage C [31]. Such inconsistencies also reflect the constraints on hospital resources and pressure on staff generated by the rapidly increasing number of eligible cases to be evaluated by the Therapeutic Committee every week.

Only 15 patients in our study (5\%) lived more than 4 hours of travel from the Day Hospital, which may not be representative of patients in ART programmes at other hospitals. A survey of patients initiating ART from 2002 to 2005 in Limbe Provincial Hospital, the only ART clinic serving the Southwest Province of Cameroon at the time of the study, showed that $44.3 \%$ of patients were living more than $40 \mathrm{~km}$ by inaccessible road from the clinic [19]. As treatment scale-up programmes are currently attempting to shift ART delivery to health districts in remote areas, more research is needed on geographic access to ART.

Only 312 out of 440 originally eligible patients were included in our study cohort. Such high attrition rates before initiating ART treatment are a main source of selection bias in studies of retention rates in Africa. Data from different cohorts in other lower-income settings [2] suggest that about $50 \%$ of patients lost early to follow-up may have died. This phenomenon needs to be better understood to enable targeted interventions. Without an informed consent, we were not allowed to review all medical records in detail to assess if baseline characteristics of the initial eligible population differed from our cohort.
Our study focused on the first six months of follow-up after ART initiation, a period previously characterized by high attrition $[5,18,19,32]$ and thus considered to be a crucial phase for promoting adherence. As level of adherence and its predictors may vary over time, we strongly encourage ART programs to conduct long-term surveillance of these outcomes to fully understand the subtle variations of its dynamic behavioral process.

\section{Conclusion}

Although there is no 'gold standard' for the assessment of medication adherence, pharmacy-refill adherence or other easily accessible methods should be considered as an alternative to CD4 count monitoring for identification of patients at risk of virological failure, especially in lowincome countries. It represents a simple, inexpensive and accurate method that correlates with virological response to treatment. Data from pharmacy refill charts should be made available to health-care workers to help identifying patients at greatest risk of treatment failure.

It is still difficult to pinpoint determinants of non-adherence to ART in lower-income countries; for example, our study indicates than the role of economic status is more complicated than may previously have been thought. Preventing treatment discontinuation by enhancing adherence counselling for a higher-risk population may not be effective: all previous studies failed to clearly demonstrate a specific group that would benefit from such intervention. Developing strategies should rather focus on improving adherence follow-up by simple and inexpensive measurement.

Finally, more studies in resource-limited countries are urgently needed to understand the underlying reasons for late initiation of ART and for high attrition rates before initiating ART, which account for a large number of early losses to follow-up and deaths in lower-income countries.

\section{Abbreviations}

AIDS: Acquired immune deficiency syndrome; ART: Anti retroviral treatment; $\mathrm{CDC}$ : Centers for disease control and prevention; CI: Confidence interval; HIV: Human immune deficiency virus; IQR: Inter quartile range; NNRTI: Non- Nucleoside reverse transcriptase inhibitor; NRTI: Nucleoside reverse transcriptase inhibitor; OR: Odds ratio; P: P value for statistical significance; PLHIV: People living with human immune deficiency virus; SD: Standard deviation; WHO: World Health Organization; YCH: Yaoundé Central Hospital.

\section{Competing interests}

The authors declare that they have no competing interests. 


\section{Authors' contributions}

All authors read and approved the final manuscript. MR conceived the study, raised funds, participated in the design and coordination of the study, collected and cleaned data, interpreted data, drafted the manuscript. BES contributed to the design and coordination of the study, contributed to data entering and cleaning, participated to interpreted and helped in drafting and revising the manuscript. NE contributed to data cleaning, performed statistic analysis and interpretation, and helped in revising the manuscript. PN conceived the study, participated in the design and coordination of the study, carried out data collection, coordinated laboratory sample processing, contributed to manuscript revision. All authors read and approved the final manuscript.

\section{Acknowledgements}

Dr Odile Ouwe Missi Oukem: laboratory expertise, Laboratoire CIRCB,

Yaoundé; Dr Mireille Claudine Essomba: pharmacy health workers coordination, Yaoundé Central Hospital; Dr Yvette Nkene and Dr Charles Kouanfack: consulting physicians at the Day Hospital, YCH; Berthe Ymele, Dora Njamnshi, Vincent Omgba: health care workers at the Day Hospital, study interviewers; Dr Edwige Belinga and Alain Ewodo: additional study interviewers; Dr Thomson Kinge: scientific advisor and technical assistance; Bibiane Bekono Ntsama: data cleaning and processing; Dominique Roulin, Prof Jean-François Balavoine, Eric Linder and Renaud Gautier: main financial support by Sidaccueil Association, Geneva, Switzerland; Jens Diedrich: additional financial support by Boehringer Ingelheim, Switzerland; Dr Daniel Gene and Dr François Kündig: additional financial support, La Chaux-deFond Hospital, Switzerland; Dr Sabine Yerly: laboratory expertise, Geneva Hospital Central Laboratory of Virology, Switzerland; Dr Thomas Szeless: study interviewers training and coordination; Dr Pelle Stolt and Dr Alexandra Calmy: scientific writing advisors; Prof Fritz Baumann: technical assistance.

\section{References}

I. Gilks CF, Crowley S, Ekpini R, Gove S, Perriens J, Souteyrand Y, et al:: The WHO public-health approach to antiretroviral treatment against HIV in resource-limited settings. Lancet 2006, 368(9534):505-510.

2. Brinkhof MW, Dabis F, Myer L, Bangsberg DR, Boulle A, Nash D, Schechter M, Laurent C, et al.: Early loss of HIV-infected patients on potent antiretroviral therapy programmes in lowerincome countries. Bull World Health Organ 2008, 86(7):559-67.

3. Van Oosterhout JJ, Bodasing N, Kumwenda JJ, Nyirenda C, Mallewa J, Cleary PR, et al.: Evaluation of antiretroviral therapy results in a resource-poor setting in Blantyre, Malawi. Trop Med Int Health 2005, I0(5):464-470.

4. Laurent C, Meilo H, Guiard-Schmid JB, Mapoure Y, Noel JM, M'Bangue M, et al:: Antiretroviral therapy in public and private routine health care clinics in Cameroon: lessons from the Douala antiretroviral (DARVIR) initiative. Clin Infect Dis 2005, 4I(I): I08-IIII.

5. Rosen S, Fox MP, Gill CJ: Patient retention in antiretroviral therapy programs in sub-Saharan Africa: a systematic review. PLoS Med 2007, 4(10):e298.

6. Demographic and Health Surveys Cameroon 20042009 [http://www.measuredhs.com/countries/meta data.cfm?surv id $=232 \&$ ctry id $=4 \&$ Srvy $p=$ ctry].

7. Laniece I, Ciss M, Desclaux A, Diop K, Mbodj F, Ndiaye B, et al:: Adherence to HAART and its principal determinants in a cohort of Senegalese adults. AIDS 2003, I 7(Suppl 3):SI03-SI 08.

8. Orrell C, Bangsberg DR, Badri M, Wood R: Adherence is not a barrier to successful antiretroviral therapy in South Africa. AIDS 2003, I7(9): I369-1375.
9. Weiser S, Wolfe W, Bangsberg D, Thior I, Gilbert P, Makhema J, et al: Barriers to antiretroviral adherence for patients living with HIV infection and AIDS in Botswana. J Acquir Immune Defic Syndr 2003, 34(3):28I-288.

10. Laurent C, Kouanfack C, Koulla-Shiro S, Nkoue N, Bourgeois A, Calmy A, et al.: Effectiveness and safety of a generic fixed-dose combination of nevirapine, stavudine, and lamivudine in HIV-I-infected adults in Cameroon: open-label multicentre trial. Lancet 2004, 364(9428):29-34.

II. Attaran A: Adherence to HAART: Africans take medicines more faithfully than North Americans. PLoS Med 2007, 4(2):e83.

12. Weidle PJ, Wamai N, Solberg P, Liechty C, Sendagala S, Were W, et al.: Adherence to antiretroviral therapy in a home-based AIDS care programme in rural Uganda. Lancet 2006, 368(9547): $1587-1594$.

13. Mills EJ, Nachega JB, Buchan I, Orbinski J, Attaran A, Singh S, et al: Adherence to antiretroviral therapy in sub-Saharan Africa and North America: a meta-analysis. JAMA 2006, 296(6):679-690.

14. Mills EJ, Nachega JB, Bangsberg DR, Singh S, Rachlis B, Wu P, et al.: Adherence to HAART: a systematic review of developed and developing nation patient-reported barriers and facilitators. PLoS Med 2006, 3(II):e438.

15. Amberbir A, Woldemichael K, Getachew S, Girma B, Deribe K: Predictors of adherence to antiretroviral therapy among HIVinfected persons: a prospective study in Southwest Ethiopia. BMC Public Health 2008, 8:265.

16. Etard JF, Laniece I, Fall MB, Cilote V, Blazejewski L, Diop K, et al.: A 84-month follow up of adherence to HAART in a cohort of adult Senegalese patients. Trop Med Int Health 2007, I2(10): I I91-1198.

17. Falagas ME, Zarkadoulia EA, Pliatsika PA, Panos G: Socioeconomic status (SES) as a determinant of adherence to treatment in HIV infected patients: a systematic review of the literature. Retrovirology 2008, 5:13.

18. Karcher H, Omondi A, Odera J, Kunz A, Harms G: Risk factors for treatment denial and loss to follow-up in an antiretroviral treatment cohort in Kenya. Trop Medlnt Health 2007, I 2(5):687-94.

19. Mosoko JJ, Akam W, Weidle PJ, Brooks J, Aweh A, et al.: Survival and adherence to ART in an era of decreasing drug cost in Limbe, Cameroon. 14th Conference on Retroviruses and Opportunistic Infections. (CROI); 2007 25-28 February; Los Angeles, California . Abstract 536

20. Ollivier F, N'Kam M, Midoungue C, Rey JL: Study conducted at the Yaounde University Hospital on anti-retroviral treatment compliance (Cameroon). Sante Publique 2005, I 7(4):559-568.

21. Nachega JB, Lehman DA, Hlatshwayo D, Mothopeng R, Chaisson RE, Karstaedt AS: HIVIAIDS and antiretroviral treatment knowledge, attitudes, beliefs, and practices in HIV-infected adults in Soweto, South Africa. J Acquir Immune Defic Syndr 2005, 38(2): $|96-20|$.

22. Weiser S, Wolfe W, Bangsberg D, Thior I, Gilbert P, Makhema J, et al.: Barriers to antiretroviral adherence for patients living with HIV infection and AIDS in Botswana. J Acquir Immune Defic Syndr 2003, 34(3):28I-288.

23. Chesney MA, Ickovics JR, Chambers DB, Gifford AL, Neidig J, ZwickI $B$, et al.: Self-reported adherence to antiretroviral medications among participants in HIV clinical trials: the AACTG adherence instruments. Patient Care Committee \& Adherence Working Group of the Outcomes Committee of the Adult AIDS Clinical Trials Group (AACTG). AIDS Care 2000, I 2(3):255-266.

24. Wester CW, Bussmann H, Avalos A, Ndwapi N, Gaolathe T, Cardiello $P$, et al.: Establishment of a public antiretroviral treatment clinic for adults in urban Botswana: lessons learned. Clin Infect Dis 2005, 40(7): 104I- 1044.

25. Bisson GP, Gross R, Bellamy S, Chittams J, Hislop M, Regensberg L, et al.: Pharmacy refill adherence compared with CD4 count changes for monitoring HIV-infected adults on antiretroviral therapy. PLoS Med 2008, 5(5):el09.

26. Chesney MA, Ickovics JR, Chambers DB, Gifford AL, Neidig J, Zwickl $B$, et al: Self-reported adherence to antiretroviral medications among participants in HIV clinical trials: the AACTG adherence instruments. Patient Care Committee \& Adher- 
ence Working Group of the Outcomes Committee of the Adult AIDS Clinical Trials Group (AACTG). AIDS Care 2000, I 2(3):255-266.

27. Mannheimer S, Friedland G, Matts J, Child C, Chesney M: The consistency of adherence to antiretroviral therapy predicts biologic outcomes for human immunodeficiency virus-infected persons in clinical trials. Clin Infect Dis 2002, 34(8): I I I5-I I2I.

28. Fielding KL, Charalambous S, Stenson AL, Pemba LF, Martin DJ, Wood R, Churchyard G], Grant AD: Risk factors for poor virological outcome at 12 months in a workplace-based antiretroviral therapy programme in South Africa: a cohort study. BMC Infect Dis 2008, I 6(8):93.

29. Singh N, Berman SM, Swindells S, Justis JC, Mohr JA, Squier C, Wagener MM: Adherence of human immunodeficiency virusinfected patients to antiretroviral therapy. Clin Infect Dis 1999 , 29(4):824-830.

30. Chen SC, Yu JK, Harries AD, Bong CN, Kolola-Dzimadzi R, Tok TS, King CC, Wang JD: Increased mortality of male adults with AIDS related to poor compliance to antiretroviral therapy in Malawi. Trop Med Int Health 2008, I3(4):5I3-5I9.

31. Laurent C, Bourgeois A, Mpoudi-Ngole E, Ciaffi L, Kouanfack C Mougnutou R, et al:: Tolerability and effectiveness of first-line regimens combining nevirapine and lamivudine plus zidovudine or stavudine in Cameroon. AIDS Res Hum Retroviruses 2008, 24(3):393-399.

32. Lawn SD, Myer L, Harling G, Orrell C, Bekker LG, Wood R: Determinants of mortality and nondeath losses from an antiretroviral treatment service in South Africa: implications for program evaluation. Clin Infect Dis 2006, 43(6):770-6.

Publish with Bio Med Central and every scientist can read your work free of charge

"BioMed Central will be the most significant development for disseminating the results of biomedical research in our lifetime. "

Sir Paul Nurse, Cancer Research UK

Your research papers will be:

- available free of charge to the entire biomedical community

- peer reviewed and published immediately upon acceptance

- cited in PubMed and archived on PubMed Central

- yours - you keep the copyright
BiolMedcentral 